\title{
A ATUAÇÃO DO MOVIMENTO NEGRO E AS QUESTÕES RACIAIS NO CURSO DE PEDAGOGIA DA UFSC
}

\author{
Joana Célia dos Passos \\ Eduarda Souza Gaudio
}

\begin{abstract}
Resumo
O artigo analisa o processo de institucionalização da educação das relações étnico-raciais no currículo do curso de Pedagogia da Universidade Federal de Santa Catarina (UFSC), tendo como foco a atuação do Núcleo de Estudos Negros (NEN). Para isso, estudamos documentos curriculares produzidos no interior do curso de Pedagogia, entre eles o projeto pedagógico do curso, manifestos, atas de assembleias, publicações produzidas pelo Núcleo de Estudos Negros (NEN), além de documentos nacionais que orientam a educação das relações étnico-raciais e a formação docente. O diálogo se situa numa perspectiva de descolonização dos currículos e oferece elementos capazes de evidenciar que há uma perspectiva negra decolonial em curso na sociedade brasileira. Conclui-se que a articulação entre o NEN e o curso de Pedagogia da UFSC foi primordial para impulsionar a institucionalização do debate étnico-racial no currículo do curso de Pedagogia da UFSC.
\end{abstract}

Palavras-chave: educação das relações étnico-raciais; Núcleo de Estudos Negros; curso de pedagogia

\section{THE PERFORMANCE OF THE BLACK MOVEMENT AND RACIAL ISSUES IN THE PEDAGOGY COURSE AT UFSC}

\begin{abstract}
The article analyses the process of institutionalization the education of ethnic-racial relations in the curriculum of the Pedagogy course at UFSC, focusing on the work of the Nucleus of Black Studies (NEN). For that, we studied curriculum documents produced inside the Pedagogy course, among them the pedagogical project of the course, manifests, minutes of assemblies, publications produced by the Nucleus of Black Studies (NEN), besides national documents that guide the education of ethnic-racial relations and teaching formation. The dialogue is situated in a perspective of decolonization of the curriculum and offers elements capable of showing that there is a decolonial black perspective in course in Brazilian society. It is concluded that the articulation of NEN and the Pedagogy course of UFSC was primordial to promote the institutionalization of ethnic-racial debate in the curriculum of the Pedagogy course of UFSC.
\end{abstract}

Keywords: education of ethnic-racial relations; Nucleus of Black Studies; course of pedagogy

\section{EL DESEMPEÑO DEL MOVIMIENTO NEGRO Y LOS PROBLEMAS RACIALES EN EL CURSO DE PEDAGOGÍA EN UFSC}

\section{Resumen}

El artículo analiza el proceso de institucionalización de la educación de las relaciones étnico-raciales en el currículo del curso de Pedagogía de la UFSC, centrándose en el trabajo del Núcleo de Estudios Negros (NEN). Para ello, estudiamos documentos curriculares producidos dentro del curso de Pedagogía, entre ellos el proyecto pedagógico del curso, manifiestos, actas de asambleas, publicaciones producidas por el Núcleo de Estudios Negros (NEN), además de documentos nacionales que orientan la educación de las relaciones étnico-raciales y la formación docente. El diálogo se sitúa en una perspectiva de descolonización de los planes de estudio y ofrece elementos capaces de mostrar que hay una perspectiva negra descolonial en curso en la sociedad brasileña. Se concluye que la articulación de la NEN y el curso de Pedagogía de la UFSC fue primordial para promover la institucionalización del debate étnico-racial en el plan de estudios del curso de Pedagogía de la UFSC.

Palabras clave: educación de las relaciones étnico-raciales; Núcleo de Estudios Negros; curso de pedagogía. 


\section{CONSIDERAÇÕES INICIAIS}

O presente artigo se insere no âmbito da temática da formação inicial de professores/as, oferecida no curso de Pedagogia da Universidade Federal de Santa Catarina, procurando apresentar uma análise acerca do processo de institucionalização da educação das relações étnico-raciais (ERER) no currículo.

A problemática assumida parte das deliberações apresentadas pela Lei n. 10.639/2003 e suas respectivas Diretrizes Curriculares Nacionais para a Educação das Relações Étnico-raciais e para o Ensino de História e Cultura Afro-Brasileira e Africana (BRASIL, 2004), que trazem demandas às instituições de ensino, sobretudo aquelas que ofertam programas de formação inicial e continuada de professores/as.

A pesquisa realizada por Gatti e Nunes (2009), ao analisar a composição curricular de uma amostra de 71 cursos de Pedagogia (públicos e privados), constatou que 3.107 disciplinas obrigatórias e 406 disciplinas optativas compõem o conjunto de disciplinas e nomenclaturas que são ofertadas nos cursos. Para as pesquisadoras, as disciplinas que poderiam dialogar com as DCNERER possuem pouca visibilidade no curso, além de possuírem, também, ementas que não explicitam seus conteúdos específicos.

A partir das determinações trazidas pelas DCNERER (2004), analisamos o processo de institucionalização da ERER no currículo do curso de Pedagogia da UFSC com foco para a atuação do Núcleo de Estudos Negros (NEN), organização social vinculada ao Movimento Negro. Para a realização do trabalho, elegemos a análise de documentos curriculares produzidos no interior do curso de Pedagogia, entre eles o Projeto Pedagógico do Curso, manifestos, atas de assembleias, documentos nacionais que orientam a educação das relações étnico-raciais e a formação docente e as publicações (jornais, livros, relatórios e revistas) produzidas pelo NEN.

\section{A EDUCAÇÃO DAS RELAÇÕES ÉTNICO-RACIAIS NA FORMAÇÃO DOCENTE E A DESCOLONIZAÇÃO DO CURRÍCULO}

A ideologia racial e a política de branqueamento influenciaram, diretamente, as discussões e a elaboração de projetos educacionais nas primeiras décadas do século XX. As reformas realizadas nos sistemas de educação, apesar de pretenderem a expansão do ensino público, provocaram violentas desigualdades embasadas em concepções eugênicas na tentativa de criar uma única "raça brasileira", saudável e nacionalista (DÁVILA, 2006).

Estas teorias raciais balizadas pela ideia de superioridade intelectual de um grupo social em detrimento de outro, fundamentou a política de formação de professores/as no Brasil, bem como as práticas curriculares e extracurriculares que hierarquizam as relações e continuam sendo reproduzidas até os dias de hoje. Embora as propostas curriculares para a educação básica, bem como a formação de professores/as tenham sofrido muitos avanços nos últimos anos, ainda é possível perceber a reprodução de conteúdos pautados em concepções racistas, operando de diferentes modos nos sistemas de educação.

Em contraposição à lógica racial que estrutura a sociedade, destacamos as lutas e ações efetuadas pelo Movimento Negro, compreendido como "[...] um ator coletivo e político, constituído por um conjunto variado de grupos e entidades políticas (e também culturais) distribuídos nas cinco regiões do país" (GOMES, 2017, p. 27). Nas suas diferentes formas de organização, o Movimento Negro é responsável por politizar o conceito de raça, desconstruir a ideia de inferioridade da população negra, além de desvelar o mito da democracia racial em prol da superação do racismo e promoção da igualdade racial. 
No que se refere às diferentes esferas de atuação do Movimento Negro, a educação é eleita como um espaço primordial de intervenções sociais que abrangem desde o direito ao acesso, até a descolonização dos currículos. As propostas apresentadas pelo Movimento Negro ganharam destaque nos anos de 1990, sobretudo nos contextos da produção acadêmica brasileira, pelos quais as pesquisas começaram a incorporar outros aspectos e categorias para além da dimensão socioeconômica (GOMES, 2010; PASSOS, NOGUEIRA, 2014).

As mobilizações nacionais e internacionais ocorridas a partir da década de 1990 foram fundamentais no processo de enfrentamento das desigualdades raciais, de denúncia ao racismo e de fortalecimentos dos coletivos, associando-se a diversas esferas sociais. Dentre as ações consideradas como marcos na luta do Movimento Negro, destacamos a I Marcha Nacional Zumbi dos Palmares, realizada em Brasília, no ano de 1995, que culminou na entrega do "Programa para superação do racismo e da desigualdade étnico-racial" ao presidente da República. Em 2001, a participação do Movimento Negro na organização e realização da III Conferência Mundial contra o racismo, a Discriminação Racial, a Xenofobia e Formas Correlatas de Intolerância ocorrida em Durban, na África do Sul, representou um momento imperativo no reconhecimento da existência do racismo no Brasil. Por meio desse acontecimento, o país passava a se comprometer com a construção de estratégias que buscam promover a igualdade racial, mediante a criação de políticas de ações afirmativas.

Em 2003, a discussão alcança a estrutura do Estado a partir da criação da Secretaria de Políticas de Promoção da Igualdade Racial (Seppir) e, no ano seguinte, no âmbito do Ministério da Educação, a Secretaria de Educação Continuada, Alfabetização e Diversidade (Secad). Nesse mesmo ano é sancionada a Lei n. 10.639/2003 que alterou a LDB/1996, instituindo no currículo oficial a história e cultura africana e afro-brasileira nas Redes de Ensino, modificada novamente pela Lei n. 11.645/2008, integrando a temática indígena nos currículos escolares.

Documentos foram construídos para subsidiar o trabalho com a questão étnico-racial em todas as etapas, modalidades e níveis de ensino: Diretrizes Curriculares Nacionais para a Educação das Relações Étnico-raciais e para o Ensino de História e Cultura Afro-Brasileira e Africana (BRASIL, 2004), as Orientações e Ações para a Educação das Relações Étnico-Raciais (BRASIL, 2006), o Plano Nacional de Implementação das DCNERER(BRASIL, 2009), as Diretrizes Curriculares Nacionais para a Educação Escolar Quilombola (BRASIL, 2012) e as Diretrizes Curriculares Nacionais para a Educação Escolar Indígena (BRASIL, 2012).

Além de Resoluções, é importante enfatizar a Lei n. 12.288/2010 que institui o Estatuto da Igualdade Racial, a Lei n. 12.711/2012 que estabelece cotas sociais e raciais para a entrada nas universidades federais e nos institutos federais de ensino técnico de nível médio, assim como a Lei n. 12.990/2014 que reserva aos/as negros/as 20\% das vagas oferecidas nos concursos públicos para provimento de cargos efetivos e empregos públicos.

Tais documentos apresentam implicações às Instituições de Ensino Superior (IES), sobretudo aquelas que ofertam a formação de professores/as, ao propor uma reeducação das relações étnico-raciais e indicar possibilidades outras de se relacionar com os diferentes grupos sociais que compõem a sociedade.

Dessa forma, a ERER e o ensino de história e cultura afro-brasileira e africana deverão ser incluídos pelas instituições de ensino, por meio de conteúdos, competências, atitudes, valores e princípios que tratam da consciência política e histórica da diversidade, do fortalecimento de identidades e direitos e das ações educativas de combate ao racismo e as discriminações. De acordo com as DCNERER (BRASIL, 2004), a questão racial deverá ser incluída na matriz curricular dos cursos de formação de professores/as, considerando os aportes teóricos, conceituais, políticos e práticos que abrangem as relações raciais no Brasil. Para além dessas orientações, o Plano Nacional de Implementação das DCNERER (BRASIL, 2009) atribui relevância à formação inicial e 
continuada de professores/as, definindo estratégias que englobam não só o ensino, como também a pesquisa e a extensão.

As deliberações apresentadas pelos documentos evidenciam a responsabilidade das IES com a oferta de cursos de formação de professores/as que promovam uma educação para as relações étnico-raciais, subsidiada pela produção e disseminação de conhecimentos que reconheçam a importância da população negra no processo de formação do país. Levando em consideração a atuação dos futuros/as professores/as na educação de crianças, jovens e adultos brasileiros/as, é primordial que a formação contemple uma pedagogia antirracista, buscando superar as desigualdades de acesso e permanência nesses espaços, a fim de promover a igualdade racial na educação básica.

Os documentos e materiais elaborados para subsidiar as legislações se inserem num conjunto de estratégias e ações produzidas pelo Movimento Negro que procuram enfrentar a descolonização dos currículos educacionais, demarcados historicamente pelo cânone eurocêntrico. Tais ações problematizam a constituição dos currículos acadêmicos, balizados por uma lógica colonial que fixa ideias de gênero, raça, sexualidade, classe, território e identidades. Essas concepções contribuem para a definição das bases curriculares, dos referenciais bibliográficos, dos materiais didáticos, das teorias pedagógicas, das metodologias, assim como das relações estabelecidas entre docentes e discentes.

Nessa discussão, defendemos com base em Gomes (2018), uma descolonização dos currículos numa perspectiva negra e brasileira, levando em consideração os movimentos de emancipação protagonizados por negras e negros, buscando reconhecê-los como sujeitos produtores de conhecimentos. Tais lutas e reivindicações, efetuadas pelos movimentos, trouxeram para as universidades temáticas desprezadas pelo cânone acadêmico, tais como a discriminação racial, as populações indígenas e quilombolas, a saúde da população negra, as ações afirmativas, a constituição das infâncias e da juventude negra, as religiões afro-brasileiras, o mito da democracia racial, o acesso e a permanência de negros/as na educação, a ideologia de branqueamento e os privilégios da branquitude, entre outros assuntos de suma importância para a promoção da igualdade racial e da garantia da democratização do país.

Ao questionar o cânone ocidental, o Movimento Negro apresenta possibilidades outras de compreender a história, a partir das próprias experiências vivenciadas nos mais de 500 anos de luta das populações afrodiaspóricas, protagonizadas pela “[...] luta política das mulheres negras, dos quilombolas, dos diversos movimentos negros, do povo de santo, dos jovens da periferia, da estética e arte negra, bem como de uma enormidade de ativistas e intelectuais" (BERNARDINOCOSTA, MALDONADO-TORRES, GROSFOGUEL, 2019, p. 10).

Nesse sentido, reconhecemos que as ações e estratégias de resistência política e epistêmica produzidas pelas populações negras integram um projeto decolonial, ao confrontar o sistema racial, sexual, patriarcal e colonial que baliza as relações sociais no Brasil, e apresenta possibilidades outras de compreender a própria história do país, a partir das experiências geradas pela colonialidade, reconhecendo saberes e conhecimentos ignorados e desperdiçados pela modernidade (GROSFOGUEL, 2010).

No âmbito das produções, a educação tornou-se um dos eixos centrais das propostas do Movimento Negro de emancipação social, apresentando um conjunto de políticas curriculares que buscam o reconhecimento, valorização e reparação dos danos ocasionados pelo racismo e abandono da população negra no pós-abolição. Como mencionamos, as IES que ofertam a formação inicial de professores/as recebem atenção primordial na configuração de tais políticas curriculares, na medida em que a atuação dos/as professores/as formados/as por estas poderá contribuir para a promoção da igualdade racial nos diversos âmbitos da educação, sobretudo, na educação básica. 
Consideramos que as DCNERER (BRASIL, 2004) e seu Plano de Implementação (BRASIL, 2009) apresentaram deslocamentos políticos, epistemológicos e práticos aos currículos educacionais, cabendo aos cursos de formação de professores/as a responsabilidade pelo cumprimento de tais resoluções.

\section{A ATUAÇÃO DO NÚCLEO DE ESTUDOS NEGROS NAS PROPOSIÇÕES DA EDUCAÇÃO DAS RELAÇÕES ÉTNICO-RACIAIS}

Nesta seção, nos centramos em evidenciar a atuação do Núcleo de Estudos Negros e do curso de Pedagogia da UFSC na implementação da ERER. Nossa intenção é afirmar sempre que as contribuições dos movimentos negros e a luta antirracista democratizam a educação brasileira.

O Núcleo de Estudos Negros (NEN) é uma organização do movimento negro, fundada em 1986, por estudantes universitários e ativistas negros/as. De acordo com seu estatuto, “[...] tem por finalidade o combate ao racismo e a promoção da igualdade racial para a justiça social e o desenvolvimento sustentável" (NEN, Estatuto, 2015. Art $2^{\circ}$ ). Organizado em programas, que se modificam de acordo com suas estratégias políticas para o enfrentamento ao racismo, faz da educação, desde sua fundação, seu principal instrumento para efetivar seu objetivo — o combate ao racismo.

Um conjunto de documentos (jornais, relatórios, livros e revistas) analisados para esse artigo explicitam as estratégias políticas da entidade em diferentes momentos. Em todos os registros encontramos, fortemente, a marca da luta contra o racismo, a denúncia do mito da democracia racial, a ausência do Estado em promover políticas para a promoção da igualdade. São documentos produzidos em diferentes períodos e por diferentes membros ou militantes que contribuíram e/ou contribuem para/com a história do movimento negro na sociedade catarinense e brasileira.

Ao longo dos anos o Programa de Educação desenvolveu estratégias e ações que tornaram a organização reconhecida nacionalmente. Conforme Lima (2009), essas “[...] iniciativas que vão dar ao NEN um status de entidade nacional especializada no campo educacional" (LIMA, 2009, p. 253). Destacamos a seguir as principais estratégias e ações políticas do NEN para uma educação antirracista:

1. A aprovação de legislação propondo alteração curricular. O NEN teve papel fundamental para a luta em prol da legislação (Lei n. 10.639/2003), ao assessorar a criação de leis municipais semelhantes: como em Itajaí, com a Lei n. 2.830/1993; em Tubarão, a Lei n. 1.864/1994; em Criciúma, a Lei n. 3.410/1997; e em Florianópolis, a Lei n. 4446/1994.

2. A formação de educadores/as foi desde sempre uma questão inerente à luta antirracista, que se amplia e assume vários formatos com a aprovação das leis municipais citadas. Além de apresentar os conteúdos sobre a história e cultura afro-brasileira e africana, o NEN vai atuar de modo a discutir e disputar a concepção de escola, de projeto político pedagógico, de currículo, de conhecimentos, de plano de educação, entre outros.

3. Para subsidiar a ação docente foi criado o Centro de Referência em Material Didático. Construiu jogos didáticos, mapa do Continente Africano em forma de quebra cabeça, fantoches com personagens negros e produziu os vídeos: "O que é movimento negro?" e "O que é capoeira?”. Colocou à disposição pública aproximadamente 250 títulos, oriundos de doação dos próprios membros, para consulta dos/as professores/as.

4. A divulgação e disseminação de elaboração, principalmente, de estudiosos/as negros/as para fortalecer a formação de educadores/as. Nesse sentido, criou o Jornal Educa-Ação Afro (19952006) que se vai constituir numa importante referência sobre relações raciais destinada a educadores/as, distribuídos em âmbito nacional. Organizou o livro: "O que você pode ler sobre o 
negro", que consistia em indicações bibliográficas sobre o tema, num período em que não havia grande volume de produção acadêmica à disposição e nem o acesso à rede de internet, como se tem hoje. Entre 1995 e 2006, publicou um conjunto de nove livros sob a "Série Pensamento negro em Educação", com diferentes temáticas. Nos anos 2000, o NEN publicou a Revista Pedagogia da Vida, na qual apresenta o resultado de um projeto de educação desenvolvido com comunidades negras rurais e, também, duas edições da Revista Nação Escola, em 2003 e 2004, que tinha como objetivo divulgar experiências de práticas pedagógicas antirracistas no âmbito das escolas públicas em diálogo com a concepção da Pedagogia Multirracial e Popular. A realização de encontros de âmbito nacional com temas específicos sobre a educação também foi protagonizado pelo NEN: em 2003, o I Encontro Nacional Negros e Educação, "Construindo políticas públicas para a promoção da igualdade racial"; e, em 2004, o II Encontro Nacional Negros, Negras e Educação "Educar o Brasil com raça construindo uma pedagogia multirracial e popular". Em 2006, o NEN promoveu o Colóquio "Pensamento Negro em Educação", que resultou na apresentação e proposta da instalação da comissão responsável pela elaboração das políticas afirmativas na UFSC.

5. Por fim, destacamos o processo de elaboração da Pedagogia Multirracial e Popular. Passos e Silva (2010) informam que a denominação Pedagogia Multirracial e Popular aparece pela primeira vez, em 1991, na formulação de um projeto de formação de educadores/as. Na análise por nós realizada, chama a atenção que na primeira edição do Jornal Educa-Ação Afro (1995), encontra-se o artigo "Descolonização curricular: escola para todos", em que o NEN propõe a construção de uma proposta pedagógica multirracial capaz de se contrapor à ideia hegemônica da branquitude como única referência. Destaca-se, aqui, o vanguardismo da ideia/conceito de descolonização curricular, e a expressa luta contra a colonialidade do poder, do saber e do ser (QUIJANO, 2010), hoje presente em tantos discursos e referenciais teóricos no campo da educação:

Propomos a introdução de uma proposta pedagógica multirracial que compreenda a diversidade étnica e cultural de que é composta a sociedade brasileira e, atue na perspectiva de que o outro é parte do todo social no mundo dos homens em contraposição a compreensão dominante de que o outro aqui o negro, é parte marginal do todo social do mundo dos brancos (NOGUEIRA, ROMÃO, 1995).

No relatório de 2002, a pedagogia aparece como uma estratégia central: "Desenvolver a proposta pedagógica multirracial e popular na perspectiva de construir novas metodologias sobre as relações raciais na educação e na pesquisa e criar recursos didático-pedagógicos afro-brasileiros com a finalidade de combater o racismo e promover a igualdade na escola brasileira" (NEN, 2002, p. 12).

De acordo com Passos e Silva (2010), os processos pedagógicos vivenciados pelo NEN, nos diferentes tempos e espaços de atuação, sua participação na formulação de políticas públicas, as práticas educativas do movimento negro, os estudos que têm como foco as relações raciais no Brasil, bem como os estudos no campo do currículo fazem com que membros do NEN sintam a necessidade e a responsabilidade de sistematizar e formular a Pedagogia Multirracial e Popular em contraposição ao modelo pedagógico pautado na hegemonia de uma única cultura, eurocêntrica e carregada de preconceitos em relação às culturas de origem africana e dos povos indígenas, do mesmo modo que as culturas populares que se desenvolvem nos centros urbanos e rurais.

Mas, a Pedagogia Multirracial e Popular não é resultado somente do pensar e atuar sobre a realidade das escolas brasileiras e as desigualdades na escolarização de negros/as, ela também resulta da relação direta com as comunidades negras. Essa "[...] radicalização de pensar e desenvolver projetos educativos em outros espaços não escolares vai se constituir num dos núcleos epistemológicos para a construção da pedagogia multirracial e popular" (PASSOS, SILVA, 2010, p. 73). 
Como pode se perceber, o NEN, ao longo de sua história, desenvolve estratégias no campo da educação que vão impactar as políticas educacionais, o pensamento educacional e as práticas pedagógicas. Identifica-se, em sua atuação, a existência de uma perspectiva negra acerca da educação e da escola brasileira, com potencial para incidir sobre a base colonial da sociedade brasileira. Nesse sentido, concordamos com Gomes (2018), quando afirma que o movimento negro com atitude e compromisso político epistemológico, traz para as Ciências Humanas e Sociais, em especial para a educação, "[...] a perspectiva negra decolonial brasileira, uma das responsáveis pelo processo de descolonização dos currículos e dos conhecimentos no Brasil" (GOMES, 2018, p. 223). Não obstante, essa perspectiva implica a "[...] luta contra a colonialidade do poder, do saber e do ser articulada contra as desigualdades socioeconômicas, raciais, de gênero e de sexualidade" (GOMES, 2018, p. 226).

O curso de Pedagogia da UFSC e os tensionamentos em torno da educação das relações étnico-raciais

O curso de Pedagogia da UFSC foi o primeiro do estado de Santa Catarina, fundado no ano de 1960, incorporado ao conjunto das seis faculdades que originaram a UFSC (Direito, Farmácia e Odontologia, Medicina, Engenharia, Serviço Social e Filosofia). Em 1962, o curso de Pedagogia passou a ser estruturado pelo Departamento de Ciências Pedagógicas ligado à Faculdade de Filosofia, Ciências e Letras (FFCL), tendo como objetivo a formação de licenciados/as para o trabalho docente em escolas normais e bacharéis para exercer o cargo de "técnico em educação".

As décadas subsequentes foram marcadas por conflitos, negociações e disputas em âmbitos locais e nacionais sobre a concepção da Pedagogia como campo de conhecimento e o perfil profissional a ser formado nesse curso (PIMENTA, 2017). Na UFSC, a defesa dos/as envolvidos/as com o curso de Pedagogia tencionava uma formação comprometida com a escola pública de qualidade e democrática. As deliberações provocadas pelas Diretrizes Curriculares Nacionais para o Curso de Pedagogia (BRASIL, 2006), mediante os Pareceres CNE/CP n. 05/2005 e CNE/CP n. 03/2006, bem como a Resolução CNE/CP n. 01/2006, demandou um conjunto de mudanças na estrutura, organização e fundamentação dos cursos, a contar pela exigência da extinção das habilitações.

O Projeto Pedagógico do curso de Pedagogia da UFSC, datado de 2008, assume a docência como princípio da formação, fundamentada por três eixos principais: a educação e infância; organização dos processos educativos e pesquisa. A proposta compreende a docência como foco do processo formativo e permite ao/a egresso/a do curso de Licenciatura em Pedagogia atuar na educação infantil, nos anos iniciais do ensino fundamental e na coordenação de atividades educacionais, assumindo o compromisso com uma educação pública de qualidade (UFSC, 2008).

No que tange às questões étnico-raciais, o Projeto ressalta a "[...] preocupação com a formação para o atendimento de jovens e adultos inseridos nos processos de escolarização inicial, para as relações étnico-raciais e para as especificidades que caracterizam a prática pedagógica na educação especial" (UFSC, 2008, p. 19, grifo nosso).

É a atuação antirracista e a produção teórica consistente que leva o NEN a ser uma das entidades convidadas a integrar o colegiado do curso de Pedagogia da UFSC. A representação do NEN, com argumentos ancorados na proposição da Pedagogia Multirracial e Popular, sustentou ao longo dos anos - 2003 e 2004 - a urgência do curso de Pedagogia contemplar em suas atividades acadêmicas a crítica aos processos racistas que permeiam o cotidiano das práticas escolares, como também a gestão educacional e as políticas públicas.

Com dados e análises substantivas sobre a educação e as relações raciais no Brasil, logrouse alcançar a disposição de aprovar no colegiado do curso a criação de uma disciplina a ser ofertada 
como optativa, posto que as diretrizes curriculares novas já estavam em processo de discussão. Embora a disciplina optativa não tenha sido aprovada, dada a necessária tramitação burocráticoadministrativa, foi viabilizado naquele ano um curso de extensão, com carga horária de 54 horas e o equivalente a 3 créditos, em encontros semanais, sob a responsabilidade da Prof ${ }^{a}$. Dra ${ }^{a}$. Vânia Beatriz Monteiro da Silva e com a participação de educadores/as do NEN. Docentes da rede pública e estudantes de licenciaturas foram beneficiados/as. Enquanto isso tramitava a aprovação da disciplina.

Quando da apresentação de defesa para a deliberação administrativa sobre a oferta de disciplina optativa, em 2005.1, encontramos:

A presente proposta origina-se das discussões ocorridas no Colegiado de Pedagogia no ano de 2004, em decorrência da preocupação em ampliar as oportunidades de formação político-educacional para acadêmicas/os do Curso de Graduação Licenciatura em Pedagogia. Naquele fórum, fomos instigadas/os em nossos debates sobre a formação docente, pela crítica histórica da discriminação negativa que experienciam crianças, jovens e adultos "negros", e em especial pelas contribuições de representantes do Núcleo de Estudos Negros/SC. Concomitantemente, tivemos a divulgação cada vez maior, dos estudos promovidos sobre condições de vida (de modo geral) oriundos de institutos como o IPEA (Instituto de Pesquisa Econômica Aplicada), Fundação Carlos Chagas e uma diversidade de trabalhos acadêmicos, como também, as demandas originadas pela Lei $\mathrm{n}^{\circ}$ 10.639, que alterou a LDBEN/96, inscrevendo artigos com foco na problemática da chamada "diversidade étnico-racial". Assim, distintos ingredientes levaram ao desenvolvimento da atividade de extensão Educação das relações raciais e práticas pedagógicas, com a participação de dois educadores populares do Núcleo de Estudos Negros/SC no atual semestre letivo, com a expectativa sugerida naquele colegiado, da sua 'evolução' para a condição de atividade curricular no formato de disciplina optativa (PROPOSTA DE OFERTA DE DISCIPLINA, 2005).

Naquele momento, um conjunto de elementos esteve integrado ao panorama do Centro de Ciências da Educação (CED) e da própria Universidade no cenário das políticas de promoção da igualdade racial, os quais animaram e subsidiaram a defesa pela formação na ótica do debate das relações étnico-raciais. Embora o número de docentes com atuação em torno da temática tenha sido muito pequeno - aproximadamente quatro docentes desenvolviam ações contínuas de interface - alcançou-se o reconhecimento necessário para aprovar a oferta da disciplina optativa pelo Departamento de Metodologia de Ensino. Denominada "Estudos sobre educação dos negros no Brasil", com 4 créditos, cuja ementa contemplava: "[...] educação, relações sociais e os negros no Brasil. Cultura e processos identitários. Escola, currículo e projetos pedagógicos para igualdade de oportunidades educacionais" (PROPOSTA DE OFERTA DE DISCIPLINA, 2005), num contexto acadêmico em que as análises das questões educacionais ainda primam por privilegiar a dimensão política de classe social.

Nos debates sobre alteração curricular, em 2007.2, a proposta de a disciplina "Estudos sobre educação dos negros no Brasil" tornar-se obrigatória, não logrou êxito, indicando que as forças curriculares em disputa não a identificavam como prioridade compartilhada entre docentes e estudantes, no desenho curricular da formação docente. Contudo, embora tenha oscilado entre eletiva e obrigatória, foi possível a aprovação da disciplina "Diferença, Estigma e Educação" com uma ementa que não explicitava as questões étnico-raciais. Na assembleia final, a $\operatorname{Prof}^{a}$. Dra ${ }^{a}$. Vânia Beatriz Monteiro da Silva, instigada pela então recente aprovação da política de ações afirmativas para o vestibular da UFSC, apresenta um manifesto curricular: 
A história das disciplinas escolares indica que sua emergência, fortalecimento e solidificação nos currículos resulta da atuação das múltiplas forças presentes no contexto dos arranjos de qualquer projeto educativo. O que conta, efetivamente, para algumas propostas de disciplinas, quando emergentes, seduzam um coletivo? Sua coerência com uma ideia de formação docente, compartilhada nas várias dimensões - filosófica; histórica; sociológica; antropológica; psicológica que abarca a preparação de jovens e adultos/as para a educação institucionalizada? Sua familiaridade com debates consagrados entre os planejadores de currículo? Seu apelo a temas candentes da sociedade, embora muitas vezes estes imponham senso de desafio para assumir tal proposta? A competência de sua defesa por espaço, na oferta acadêmica? (UFSC. CED. Manifesto: Em defesa da Disciplina Diferença, Estigma e Educação no currículo de Pedagogia, 2007).

A disciplina "Diferença, Estigma e Educação" conquistou lugar na primeira fase do curso, com 3 créditos e uma ementa que indica a atenção com a constituição intersubjetiva e sua implicação na vida escolar, a saber: "Teorias modernas e contemporâneas sobre o juízo perceptivo de si e do outro. Introdução ao estudo sistemático dos conceitos vinculados com os processos de diferenciação individual e social e sua repercussão no contexto escolar. Alteridade, diálogo e ética na educação" (UFSC, 2008). Naquele momento, também foi aprovado o Núcleo de Aprofundamento de Estudos (NADE) "Práticas Educativas e Relações Étnico-raciais", com 3 créditos, tendo como foco os estudos sobre temas relacionados às dinâmicas dos processos educacionais.

A exclusão da disciplina "Diferença, estigma e educação" chegou a ser proposta em vários momentos, sendo utilizado como um dos motivos a aposentadoria da professora, como se a disciplina não fosse responsabilidade do curso. A manutenção da disciplina foi defendida, sobretudo, por uma pesquisadora em relações raciais, que ingressou como docente no curso de Pedagogia, em 2013. Tal professora assumiu o oferecimento da disciplina, a partir de 2015, iniciando um processo de alteração de caráter epistemológico, consoante a demanda apresentada pelo curso de Pedagogia em discutir com centralidade a dimensão racial na formação de professores/as.

Cabe lembrar sempre que o currículo se constitui como um campo em permanente disputa. Silva (1995) alerta que as narrativas hegemônicas do currículo orientam quem pode representar a si e os outros. Que grupos devem ter voz e que grupos podem ser silenciados. Não por acaso o protagonismo para a inserção da educação das relações étnico-raciais no curso de Pedagogia foi de professoras negras. Do mesmo modo, observa-se a morosidade no percurso para a implantação de disciplinas com discussões étnico-raciais.

Recentemente (2019-2020), o curso de Pedagogia aprovou uma atualização/alteração curricular em que se instituíram as disciplinas a seguir: 
DOI: $10.12957 /$ teias. $\%$ Y.49736

Tabela 1: Disciplinas aprovadas no Ajuste Curricular do curso de Pedagogia 2019

\begin{tabular}{|c|c|c|c|}
\hline Disciplina & Ementa & $\begin{array}{l}\text { Carga } \\
\text { horária }\end{array}$ & Tipo \\
\hline $\begin{array}{l}\text { Educação e Relações } \\
\text { Étnico-Raciais }^{1}\end{array}$ & $\begin{array}{l}\text { Relações étnico-raciais no Brasil e } \\
\text { desigualdades. Principais conceitos: relações } \\
\text { raciais, relações de gênero, direitos } \\
\text { humanos, igualdade, diferença, estigma, } \\
\text { estereótipos, preconceito, identidade social, } \\
\text { branquitude e alteridade. Movimentos } \\
\text { negros. Movimentos indígenas. Política de } \\
\text { ações afirmativas na educação. Práticas } \\
\text { pedagógicas antirracistas no contexto } \\
\text { escolar. }\end{array}$ & 54 horas & $\begin{array}{l}\text { Obrigatória para o } \\
\text { Curso de } \\
\text { Pedagogia }\end{array}$ \\
\hline $\begin{array}{l}\text { Relações raciais na } \\
\text { sociedade brasileira }\end{array}$ & $\begin{array}{l}\text { Relações étnico-raciais no Brasil e } \\
\text { desigualdades. Teorias raciais. Branquitude } \\
\text { e poder. Classificação Racial. Política de } \\
\text { ações afirmativas. }\end{array}$ & 72 horas & $\begin{array}{l}\text { Optativa para } \\
\text { qualquer curso da } \\
\text { UFSC }\end{array}$ \\
\hline $\begin{array}{l}\text { NADE Práticas } \\
\text { pedagógicas e } \\
\text { relações étnico- } \\
\text { raciais }^{2}\end{array}$ & $\begin{array}{l}\text { Política de ações afirmativas na educação: } \\
\text { Diretrizes Curriculares Nacionais para o } \\
\text { Ensino de História e Cultura Afro-brasileira } \\
\text { e Africana. Práticas pedagógicas } \\
\text { antirracistas no contexto escolar. }\end{array}$ & 54 horas & $\begin{array}{l}\text { NADE - Somente } \\
\text { para estudantes do } \\
\text { curso de } \\
\text { Pedagogia }\end{array}$ \\
\hline
\end{tabular}

Fonte: Autoras, 2020.

O racismo estrutural e institucional faz com que os desafios para a consolidação da educação das relações étnico-raciais no curso de Pedagogia da UFSC ainda persistam, como exemplo, cita-se o fato de o curso contar com apenas uma professora para ministrar as disciplinas indicadas na Tabela 1. Com isso, a tendência é priorizar a disciplina obrigatória para o curso de Pedagogia em detrimento do NADE ou da optativa, que poderia atender a outros cursos e campos de conhecimentos. Além disso, entendemos que a responsabilidade em abordar conhecimentos da educação das relações étnico-raciais não é exclusiva das disciplinas citadas, mas, do conjunto dos componentes curriculares que constituem o projeto do curso. Contraditoriamente, o discurso em defesa da escola pública para todos, presente de modo unânime e inequívoco, parece dissimular a construção racial curricular eurocentrada que se materializa no projeto pedagógico, planos de ensino, ementas, bibliografias estudadas, entre outros.

Nesse sentido, concordamos com Gomes (2012) ao defender que a “[...] descolonização do currículo implica conflito, confronto, negociações e produz algo novo. Ela se insere em outros processos de descolonização maiores e mais profundos, ou seja, do poder e do saber" (GOMES, 2012, p. 107). Portanto, a descolonização curricular exige mudanças na constituição dos espaços acadêmicos, buscando deslocalizar o paradigma hegemônico eurocêntrico, reconhecendo os conhecimentos produzidos pelas populações afrodiaspóricas, historicamente ignorados e ocultados por um sistema ocidental e universal do conhecimento.

\footnotetext{
${ }^{1}$ Será oferecida pela primeira vez em 2020.2 na primeira fase do curso em substituição à disciplina Diferença, Estigma e Educação. As alterações foram sendo realizadas inicialmente no âmbito do plano de ensino em acordo com a área de Organização Escolar e com o Núcleo Docente Estruturante (NDE) do curso.

${ }^{2}$ Embora o NADE já existisse com esse nome, a ementa passou por atualização.
} 


\section{CONSIDERAÇÕES FINAIS}

O exercício aqui realizado teve duas intenções: a primeira foi explicitar que o NEN, uma organização negra, é um agente político importante na inserção das questões raciais no curso de Pedagogia da UFSC; a segunda foi situar na história da educação pública em SC práticas educacionais que ocorrem fora do âmbito da escolarização formal e do Estado, e que ainda precisam ser visibilizadas e reconhecidas nos estudos acadêmicos.

Como buscamos demonstrar, as ações desenvolvidas pelos Programas do NEN atribuem centralidade à esfera educacional como locus privilegiado de atuação política, no sentido de reconhecer a história da população negra e criar estratégias de superação das desigualdades raciais. A articulação entre membros do NEN e o curso de Pedagogia da UFSC foi primordial para impulsionar a inclusão do debate étnico-racial no currículo do referido curso de Pedagogia.

A participação dessa organização no processo de institucionalização da educação das relações étnico-raciais no currículo corrobora a concepção da importância histórica do movimento negro e das lutas antirracistas para a democratização da escola, da universidade e da sociedade brasileira de modo geral, além de evidenciar que o NEN está entre os precursores da formulação do que vem sendo chamado por Gomes (2018) de perspectiva negra decolonial brasileira.

\section{REFERÊNCIAS}

BERNARDINO-COSTA, Joaze; MALDONADO-TORRES, Nelson; GROSFOGUEL, Ramón. Decolonialidade e perspectiva negra. Revista Sociedade e Estado, v. 31, n. 1, 2016.

BRASIL. Resolução n. 1/2004. Institui Diretrizes Curriculares Nacionais para a Educação das Relações Étnico-Raciais e para o Ensino de História e Cultura Afro-Brasileira e Africana. Brasília: MEC, 2004.

BRASIL. Plano Nacional de Implementação das Diretrizes Curriculares Nacionais para Educação das Relações Étnico-raciais e para o Ensino de História e Cultura Afro-Brasileira e Africana. Brasília: MEC, 2009.

DÁVILA, Jerry. Diploma de brancura: política social e racial no Brasil (1917-1945). São Paulo: Ed. UNESP, 2006.

GATTI, Bernardete A.; NUNES, Marina Muniz R. (org.). Formação de professores para o ensino fundamental: estudo de currículos das licenciaturas em Pedagogia, Língua Português, Matemática e Ciências Biológicas. Textos FCC, São Paulo, v. 29, 2009. 155p.

GROSFOGUEL, Ramón. Para descolonizar os estudos de economia política e os estudos póscoloniais: transmodernidade, pensamento de fronteira e colonialidade global. In: SANTOS, Boaventura de Sousa; MENESES, Maria Paula G. (orgs.). Epistemologias do Sul. São Paulo: Cortez, 2010.

GOMES, Nilma Lino. Intelectuais negros e produção de conhecimento: algumas reflexões sobre a realidade brasileira. In: SANTOS, Boaventura de Sousa; MENESES, Maria Paula G. (orgs.). Epistemologias do Sul. São Paulo: Cortez, 2010.

GOMES, Nilma Lino. Relações étnico-raciais, educação e descolonização dos currículos. Currículo sem Fronteiras, v. 12, n. 1, p. 98-109, jan./abr. 2012.

GOMES, Nilma Lino. O Movimento Negro Educador: saberes construídos nas lutas por emancipação. Petrópolis, Rio de Janeiro: Vozes, 2017.

GOMES, Nilma Lino. O Movimento Negro e a intelectualidade negra descolonizando os currículos. In: BERNARDINO-COSTA, Joaze; MALDONADO-TORRES, Nelson; GROSFOGUEL, Ramón (orgs.). Decolonialidade e pensamento afrodiaspórico. São Paulo: Autêntica, 2018. 
LIMA, Ivan Costa. As pedagogias do Movimento Negro no Rio de Janeiro e Santa Catarina (1970-2000): implicações teóricas e políticas para a Educação brasileira. 2009. Tese de doutorado - Universidade Federal do Ceará. Fortaleza, 2009.

NEN. Relatório 2002. Florianópolis: Núcleo de Estudos Negros, 2002.

NEN. Estatuto. Florianópolis: Núcleo de Estudos Negros, 2015.

NOGUEIRA, João Carlos; ROMÃO, Jeruse. Descolonização curricular: escola para todos. Jornal Educa-Ação Afro, Florianópolis: NEN, n. 01, 1995.

PASSOS, Joana Célia dos; ALMEIDA, José Nilton; SILVA, Vânia Beatriz Monteiro. Relações étnico-raciais no Brasil e formação acadêmica: uma experiência de debate. In: CARVALHO, Diana Carvalho de et al. Experiências pedagógicas com o ensino e formação docente: desafios contemporâneos. Araraquara, São Paulo: Junqueira \& Marin, 2009.

PASSOS, Joana Célia dos; SILVA, Vânia Beatriz Monteiro. Contribuições do Núcleo de Estudos Negros na construção e formulação da Pedagogia Multirracial e Popular. In: NOGUEIRA, João Carlos; PASSOS, Joana Celia dos; SILVA, Vania Beatriz Monteiro (orgs.). Negros no Brasil: política, cultura e pedagogia. Florianópolis: Atilende, 2010.

PIMENTA, Selma Garrido et al. Os cursos de Licenciatura em Pedagogia: fragilidades na formação inicial do professor polivalente. In: SILVESTRE, Magali Aparecida; PINTO, Umberto de Andrade (orgs.). Curso de Pedagogia: avanços e limites após as Diretrizes Curriculares Nacionais. São Paulo: Cortez, 2017.

SILVA, Vânia Beatriz Monteiro; PASSOS, Joana Célia dos. A educaşão das relações étnico-raciais e do ensino da história e cultura afro-brasileira, africana e indigena no curso de pedagogia da UFSC. Audiência Pública do CED/UFSC. Florianópolis, 2014.

SILVA, Tomaz Tadeu da. Documentos de identidade: uma introdução às teorias do currículo. Belo Horizonte: Autêntica, 1995.

UFSC. CED. Manifesto: em defesa da Disciplina Diferença, Estigma e Educação no currículo de Pedagogia. Florianópolis, CED/UFSC, 2007.

UFSC. Projeto pedagógico do curso de pedagogia. Universidade Federal de Santa Catarina, Centro de Educação, $\quad$ Florianópolis, $2008 . \quad$ Disponível em http://pedagogia.paginas.ufsc.br/files/2013/06/PPP-Pedagogia-2008-vers\%C3\%A3o-final2.pdf. Acesso em 7 mar. 2019.

\section{Informações das autoras}

Joana Célia dos Passos

Docente da Universidade Federal de Santa Catarina

E-mail: joana.passos@gmail.com

ORCID: https://orcid.org/0000-0001-9946-7900

Link Lattes: http://lattes.cnpq.br/6523332944786091 
Eduarda Souza Gaudio

Doutoranda em Educação da Universidade Federal de Santa Catarina E-mail: eduardagaudio@gmail.com

ORCID: https://orcid.org/0000-0001-6499-6052

Link Lattes: http://lattes.cnpq.br/3306448338666208 